ISSN 0280-5316 ISRN LUTFD2/TFRT--5798--SE

\title{
HCCI Engine Modeling and Control using Conservation Principles
}

Daniel Blom

Department of Automatic Control Lund University June 2007 



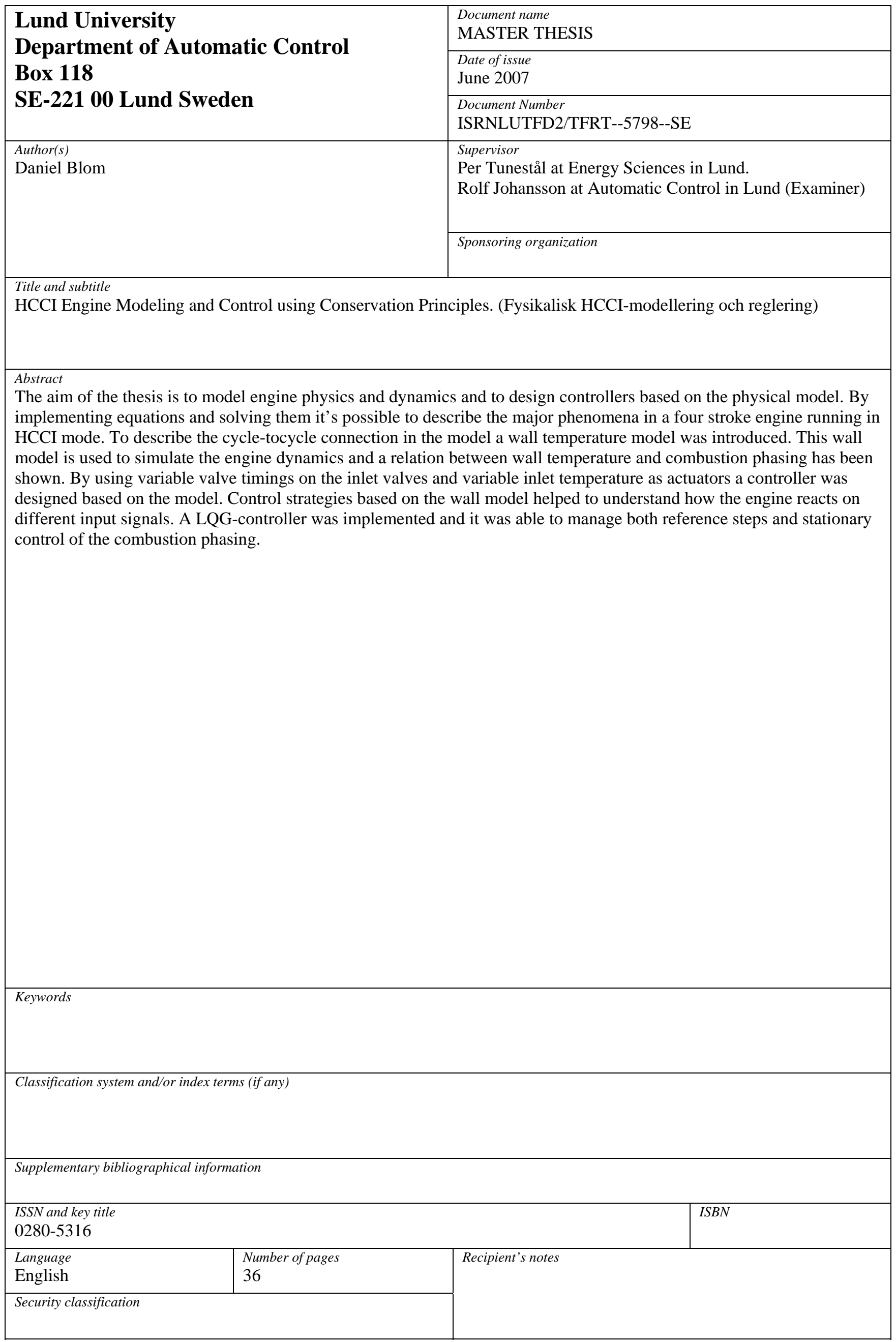

http://www.control.lth.se/publications/ 



\section{Contents}

1 Introduction 1

1.1 Background . . . . . . . . . . . . . . . . . 1

1.2 Aim of the thesis . . . . . . . . . . . . . . . . . . . 1

1.3 Related work ... . . . . . . . . . . . . . . . 1

2 Methods 2

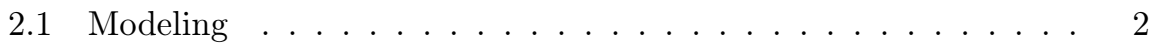

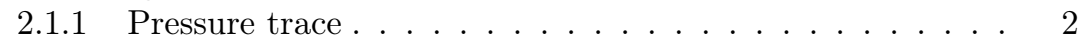

2.1.2 Temperature trace ................ . . . . 2

2.1.3 Temperature of cylinder walls . . . . . . . . . . . 3

2.1.4 Concentration of species . . . . . . . . . . . . . . 4

2.1 .5 Inflow and outflow . . . . . . . . . . . . . . . 5

2.2 Tests on the model . . . . . . . . . . . . . . . . . 5

2.2.1 Change of parameters . . . . . . . . . . . 6

2.2 .2 Noise . . . . . . . . . . . . . . . . 6

2.2.3 Wall model behavior . . . . . . . . . . . . . . 6

2.3 Experimental setup . . . . . . . . . . . . . . . . 6

2.4 Calibration of the model . . . . . . . . . . . . . . 7

2.5 Identification for control design . . . . . . . . . . . . . . . 7

2.6 Control design ..................... 8

3 Results 9

3.1 The modeling . . . . . . . . . . . . . . . . . . 9

3.2 Noise . . . . . . . . . . . . . . . . . . . . . . . 15

3.3 Wall model behavior . . . . . . . . . . . . . . . . . 16

3.4 The calibration . . . . . . . . . . . . . . . . . . 17

3.5 The identified model . . . . . . . . . . . . . . . . . . . . . . 17

3.6 The controller . . . . . . . . . . . . . . . . . 17

4 Discussion $\quad \mathbf{2 3}$

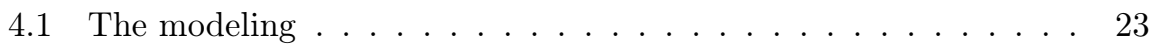

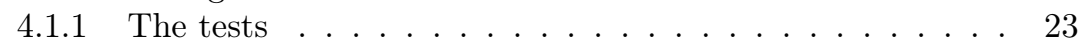

4.2 The identified model . . . . . . . . . . . . . . . . . 25

4.3 The controller . . . . . . . . . . . . . . . . 25

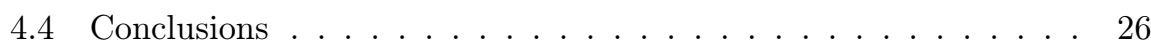

4.5 Further development . . . . . . . . . . . . . . . 26

$\begin{array}{lll}5 & \text { Bibliography } & 27\end{array}$

A Appendix $\quad \mathbf{2 8}$

A.1 Calculation of masses before and after combustion . . . . . . . 28

A.2 The Simulink model . . . . . . . . . . . . . . . . . . . 31 



\section{Introduction}

\subsection{Background}

Today's increasing number of heavy duty vehicles and more intense transportation affect the global pollution of the air. The exhausts from diesel engines contain mainly two substances which are troublesome to human health. These are soot and nitrogen oxides, $\mathrm{NO}_{x}$. The soot can be removed either by filtering the exhausts or by using an alternative fuel such as dimethyl ether, DME [1]. The $\mathrm{NO}_{x}$ is more difficult to remove. Since the diesel cycle contains a diffusion flame which burns under both rich and lean circumstances the formation of $\mathrm{NO}_{x}$ can become significant due to the high combustion temperature. To lower the formation of $\mathrm{NO}_{x}$ it is possible to let the combustion become more homogeneous and diluted which will cause a slower burning rate with lower combustion temperature.

The HCCI (Homogenous Charge Compression Ignition) concept is one way towards an engine with cleaner exhausts. The HCCI engine has a great difficulty which is the fact that it is hard to control the point of auto-ignition. The desired combustion phasing takes place around top dead center, TDC, and to maintain this phasing from cycle-to-cycle a controller of some sort is needed.

\subsection{Aim of the thesis}

The aim of the thesis is to model engine physics and dynamics. These results are then used to design controllers without a system identification of the engine. Further, the aim is to find parts of the model which are essential when it comes to describe the major phenomena of the engine.

\subsection{Related work}

The Department of Automatic Control and the Division of Combustion Engines at the Lund Institute of Technology are working together in the development of control strategies for the HCCI engine process. Different types of approaches have been tested such as chemical based models for control and system identification of the engine. These models have been a base for development of different control strategies including PID and the more computing intense model predictive control [2]. The actuators tested include the well known variable valve actuation system used to vary the valve timings and dual fuel. To be able to convert existing engines to HCCI mode, focus on the diesel fuel and advanced injection strategies is now the main area of interest. 


\section{Methods}

\subsection{Modeling}

To model the complexity of combustion engines there are some parts which are essential. These parts need to represent the different states of the engine to make the model to give correct trends under different loads and parameters. The states are assumed to be in-cylinder states. One engine cycle is assumed to begin when the piston is at the top with minimal cylinder volume and the inlet valve is open. The cycle then proceeds with the inlet phase, the compression phase, the expansion phase and the outlet phase.

\subsubsection{Pressure trace}

It is assumed that the pressure around the engine is atmospheric $(\sim 1$ bar $)$ and the pressure of the inlet manifold the same. The later pressure can be adjusted (typical $\sim 2$ bar) if a turbocharger is used. The in-cylinder pressure during the inlet phase must be lower than the inlet manifold. Otherwise the gas won't flow into the cylinder. If the inlet valve closes before the piston reaches the bottom, pressure will drop further due to the ideal gas law which is assumed to be a good approximation.

Under the compression phase the pressure will rise rapidly. The process is close to adiabatic meaning all the heat produced is transferred to the in-cylinder gas. This is due to the fast motion of the piston and the pressure will rise further. If the compression is very slow the maximum pressure will be approximately the compression-ratio times the inlet pressure. The model is expected to give a top pressure which is significantly higher than this. At this point there are two alternatives. If the charge doesn't ignite, then the pressure will drop due to the expansion. If ignition takes place the pressure will rise dramatically in no time. The peak pressure is depending on how much fuel is injected and when the ignition is triggered.

The expansion will cause the pressure to drop following an adiabatic process. The pressure in the exhaust manifold is assumed to be atmospheric. When the exhaust valve is opened the cylinder pressure will be a few bars causing a blast of gas out from the cylinder. The pressure will drop and the outlet phase will take place meaning the rest of the in-cylinder gas will be pumped out. The pressure will then be around atmospheric and the cycle is completed.

When modeling the pressure it is possible to use the ideal gas law in the form [3]

$$
p=\sum\left[X_{i}\right] R T
$$

where [] in the formula denotes concentration, $p$ is the pressure in $[\mathrm{Pa}]$ and $\left[X_{i}\right]$ is the concentration of species $\mathrm{i}$ in the cylinder in $\left[\mathrm{mol} / \mathrm{m}^{3}\right]$. $T$ is the temperature of the in-cylinder gas in $[K]$ and $R$ is the universal gas constant $R=8.31[\mathrm{~J} / \mathrm{K} \cdot \mathrm{mol}]$.

\subsubsection{Temperature trace}

The temperature of the gas can be approximated with $300 \mathrm{~K}$ in the inlet manifold. This approximation is done because the research engine is located in a lab with a surrounding temperature of $300 \mathrm{~K}$ which is a common temperature 
inside buildings. Under the inlet phase the cold gas from the inlet manifold mixes with the warm residual gas from previous cycle in the cylinder. This will cause the temperature of the in-cylinder gas to drop towards the temperature of the inlet gas.

During the compression phase the temperature will rise as mentioned in the pressure trace. The ignition is assumed to be triggered around the top dead center. The fast burning of the gas will cause the temperature to rise fast. After the combustion the expansion will cause the hot gas to cool down following the ideal gas law. When the exhaust valve is opened the temperature will drop a bit due to the high flow out of the cylinder. The in-cylinder gas will then be held around constant during the outlet phase.

The temperature can be described by the equation

$$
\dot{T}=\frac{\frac{\dot{Q}}{V}-\sum\left[\dot{X}_{i}\right] h_{c, i}-\frac{\dot{V} \sum\left[X_{i}\right] h_{c, i}}{V}+\frac{p \sum\left[\dot{X}_{i}\right]}{\sum\left[X_{i}\right]}+\frac{\dot{m}_{i c} h_{i}-\dot{m}_{c e} h_{c}}{V}}{-p / T+\sum\left[X_{i}\right] c_{p, i}(T)}
$$

This can be derived using the first law of thermodynamics see [3]. $\left[\dot{X}_{i}\right]$ is the derivative of the concentration of species i in $\left[\mathrm{mol} / \mathrm{m}^{3} \mathrm{~s}\right]$ and $h_{c, i}$ is the enthalpy of species i in $[\mathrm{J} / \mathrm{mol}] . V$ and $\dot{V}$ is the volume and the derivative of the volume in $\left[\mathrm{m}^{3}\right]$ and $\left[\mathrm{m}^{3} / \mathrm{s}\right] . \quad \dot{m}_{i c}$ and $\dot{m}_{c e}$ is the mass-flows in and out of the cylinder in $[\mathrm{kg} / \mathrm{s}] . h_{i}$ and $h_{c}$ is the enthalpy of the gas mixture in the inlet and outlet manifold in $[\mathrm{J} / \mathrm{kg}]$.

$\dot{Q}$ is the heat transfer rate to the surrounding material, the walls and piston. This can be approximated [3] by the equation

$$
\dot{Q}=-\frac{C_{1}\left(C_{2} v p\right)^{0.8}}{B^{0.2} T^{0.55}} A\left(T-T_{\text {wall }}\right)
$$

where $C_{1}=285.6$ and $C_{2}=2.28$ are constants, $v$ is the mean piston speed in $[\mathrm{m} / \mathrm{s}], p$ is the cylinder pressure in $\left[10^{-5} \mathrm{~Pa}\right], B$ is the cylinder bore diameter in $[m], A$ is the inner cylinder area in $\left[\mathrm{m}^{2}\right]$ and $T_{\text {wall }}$ is the temperature of the cylinder walls.

\subsubsection{Temperature of cylinder walls}

During the inlet phase the temperature will drop due to cooling from the cold inlet flow. When compression begins the temperature will rise and when combustion is taking place the temperature will rise to its maximum. During the expansion and outlet phase the temperature will drop due to cooling from the water around the cylinder.

To describe how the temperature of the walls changes during the engine cycle, it is possible to use a convection model. The wall is on one side cooled by the cooling water assumed to be $365 \mathrm{~K}$ when the engine has reached normal operating temperature. The other side of the wall is affected by the in-cylinder gas temperature which varies during one cycle. A simple model to describe this is

$$
\dot{T}_{\text {wall }}=-k_{1} \dot{Q}-k_{2}\left(T_{\text {wall }}-T_{\text {water }}\right)
$$

where $k_{1}$ and $k_{2}$ are constants depending on the engine and needs to be estimated by experiment, $T_{\text {water }}$ is the temperature in $[K]$ of the cooling water. 


\subsubsection{Concentration of species}

Species concentrations are expected to be constant during the intake phase. This is due to the constant ratio between number of moles and volume. If the inlet valves close before the piston reaches the bottom the concentrations will drop due to increasing volume and constant number of moles.

During the compression phase the concentrations will rise due to decreasing volume and constant number of moles. When combustion takes place the number of moles will change according to the reaction formula. The engine is run on ethanol which will lead to production of water and carbon dioxide. It is assumed that the amount of nitrogen in the cylinder from the intake air is constant and doesn't react. The intake air is assumed to contain 21 percent oxygen and 79 percent nitrogen which is a standard approximation.

The expansion phase will decrease the concentrations of the species due to increasing volume and when the exhaust valve opens the concentrations will drop a bit due to the drop of in-cylinder pressure. During the outlet phase the species concentrations will be assumed constant as in the inlet phase.

The concentration of species can be described by

$$
\left[\dot{X}_{i}\right]=w_{c o m b}+\frac{Y_{i, i} \dot{m}_{i c}}{V M_{i}}-\frac{Y_{c, i} \dot{m}_{c e}}{V M_{i}}-\frac{\dot{V}\left[X_{i}\right]}{V}
$$

and

$$
Y_{c, i}=\frac{\left[X_{i}\right] M_{i}}{\sum\left[X_{i}\right] M_{i}}
$$

where $Y_{i, i}$ and $Y_{c, i}$ are the mass fractions of species $\mathrm{i}$ in the inlet manifold and cylinder [3]. $M_{i}$ is the molar mass of species i in $[\mathrm{kg} / \mathrm{mol}]$ and $w_{\text {comb }}$ is the rate of change of the burning fuel in $\left[\mathrm{mol} / \mathrm{m}^{3} \mathrm{~s}\right]$.

To trigger the combustion an integrated Arrhenius rate threshold [4] is used. This is an approximation of all the sub reactions taking place in the complex reaction process.

$$
K=\int_{\theta_{I V C}}^{\theta_{i g n}} A e^{\frac{-E a}{R T}}[F]^{a}\left[O_{2}\right]^{b} d \theta
$$

Here is $[F]$ the concentration of the fuel in $\left[\mathrm{mol} / \mathrm{m}^{3}\right]$ and the subscript ign means the point when combustion is triggered. Further, the subscript $I V C$ means inlet valve closure and $A$ and $E_{a}$ is constants depending on the chemical reaction. The integral grows along the compression phase and when it reaches a threshold, $\theta_{i g n}$ is stored and used as the angle of ignition. The threshold must be determined via experiment. When ignition is detected the rate of burning $w_{\text {comb }}$ is described by a Wiebe function which is adjusted for HCCI combustion [3].

$$
w_{c o m b}=\frac{[F]_{i g n} a(m+1)\left(\frac{\theta-\theta_{i g n}}{\Delta \theta}\right)^{m}}{\frac{V \Delta \theta}{V_{i g n} \dot{\theta}} e^{a\left(\frac{\theta-\theta_{i g n}}{\Delta \theta}\right)^{m+1}}}
$$

In this function $a$ and $m$ is parameters to shape the function and $\Delta \theta$ is the duration of the combustion. 
The reaction formula of the fuel with the air can be used to determine the rate of change of species due to combustion of the fuel. For ethanol with air it is

$$
\mathrm{C}_{2} \mathrm{H}_{5} \mathrm{OH}+3 \mathrm{O}_{2}+11.3 \mathrm{~N}_{2} \longrightarrow 2 \mathrm{CO}_{2}+3 \mathrm{H}_{2} \mathrm{O}+11.3 \mathrm{~N}_{2}+\text { Energy }
$$

which leads to the following: $w_{\text {comb }}$ for oxygen is 3 times higher than for the fuel. For water and carbon dioxide the rates are -3 and -2 times the fuel rate. The nitrogen is approximated to be constant. In a real combustion process there will be some production of $N O_{x}$.

\subsubsection{Inflow and outflow}

Both flows are direct dependent of the pressure differences in the cylinder, inlet and outlet manifolds. The flows are expected to increase when piston speed is increased. When the exhaust valve opens the in-cylinder pressure will lead to a high flow out from the cylinder until the pressures on both sides of the valve have stabilized.

To model the flows some approximations are needed which are suggested in [3]. The equation of the mass flow is

$$
\dot{m}=\frac{C_{d} A p_{0}}{\sqrt{R T_{0}}}\left(\frac{p_{T}}{p_{0}}\right)^{1 / \gamma}\left(\frac{2 \gamma}{\gamma-1}\left(1-\left(\frac{p_{T}}{p_{0}}\right)^{\frac{\gamma-1}{\gamma}}\right)\right)^{1 / 2}
$$

where $\dot{m}$ is the mass flow in $[\mathrm{kg} / \mathrm{s}]$ and $C_{d}$ is the coefficient of discharge which depends on the geometry of the inlet. $A$ is the area of the inlet approximated by the area of the valve minus the area of the valve-shaft. $p_{0}$ is the pressure on the side of the valve where the mass is expected to flow from in $[P a]$ and $p_{T}$ is the pressure on the other side of the valve. $T_{0}$ is the temperature on the side of the valve where the flow is directed to and $\gamma$ is the coefficient of the compressible gas assumed to be 1.35. This equation assumes that the ratio between the two pressures is small enough that the flow doesn't get choked.

\subsection{Tests on the model}

All the modeling work is done in MATLAB and Simulink. The model is initiated by a script which defines all the constants and calculates the enthalpy of the species at the given temperature of the inlet gas. The model simulates one engine cycle and saves the different states to the next cycle. These states are temperature of in-cylinder gas, in-cylinder enthalpy of species, wall temperature and concentrations of residual species. The Arrhenius rate threshold and the two coefficients from the wall modeling are given test parameters. These need some adjustment when evaluating the model with the real engine. Further, the CA50 is defined as the crank angle, CAD, where $50 \%$ of the fuel is burnt.

Tests on the model are essential in two cases. The first is to verify that it performs as expected in the theory above and to find interesting results, and the second is to see how well the model behaves when noise is introduced on some signals. The tests will therefore be divided into two groups. 


\subsubsection{Change of parameters}

1. Pressure changes due to valve opening and closing.

2. Pressure rises fast due to combustion.

3. The first cycle is a cold startup cycle meaning that the in-cylinder gas temperature will be equal to inlet temperature. This test serves to see how the in-cylinder gas temperature changes from the first cycle to the next ones.

4. The exhaust temperature is hotter than the inlet temperature.

5. How a step in inlet temperature affects the CA50.

6. Temperature of the walls behaves as expected.

7. The variations of the temperature of the walls from cycle to cycle are small.

8. The mass before and after the ignition is the same.

9. Inflow and outflow follows the theory.

10. How CA50 depends on a step in rpm.

11. How more injected fuel affects CA50.

12. How the inlet valve closure affects CA50.

\subsubsection{Noise}

The different signals are disturbed by both white noise and a constant offset.

1. How small disturbances on the fuel concentration affect CA50.

2. How small disturbances on the temperature affect CA50.

3. How small disturbances on the wall temperature affect CA50.

\subsubsection{Wall model behavior}

To investigate the wall model closer and to verify its importance in modeling, three tests can be done. The first is to see the relation between the CA50 and temperature of the walls. The two other tests are needed to show the influence of the inlet temperature and inlet valve closure on the temperature of the walls.

\subsection{Experimental setup}

The model was adapted to a heavy duty diesel engine from Volvo. The engine has a displacement of 12 liters and was rebuilt to be able to run in HCCI mode. The intake air can be preheated using an industrial air heater. It is possible to heat the air to over 100 degrees Celsius. The pressure in the inlet manifold could be raised to over atmospheric pressure using a turbo charger. To adjust the pressure more accurately the turbo was equipped with variable geometry which can adjust the force on the turbine blades. The engine had a 
port injection system for ethanol and common diesel injectors for direct injection of diesel into the cylinder. It was necessary for the diesel injectors that a small amount of diesel is injected every cycle to avoid overheating of the injectors. This wasn't implemented in the model but very small amounts of diesel may not affect CA50 significantly. The engine was further equipped with a variable valve timing system which make it possible to control the inlet and outlet valve timings.

\subsection{Calibration of the model}

To calibrate the model, real engine data are needed. The parameters to calibrate can be divided into two categories. The first category is geometrical parameters and parameters for the valve timings, temperatures and pressures. The second category is parameters which need step responses from the running engine. These parameters are the coefficients for the wall model and the Arrhenius rate threshold.

The second category of parameters is chosen as follows. First, the wall model needs to represent the step responses in injected fuel per cycle. By adjusting the two parameters different behavior can be shown. This behavior must follow the behavior from the engine and by looking at CA50 from the engine during a step in injected fuel per cycle the two parameters can be adjusted to follow the engine. Second, the Arrhenius rate threshold must be determined. This is done by adjusting the threshold in the model in such a way that the CA50 from the model approximates the value from the engine.

\subsection{Identification for control design}

To be able to design a controller and to do simulations with the controller, two identification experiments are needed. The first experiment assumes to have two inputs and one output. The inputs are inlet temperature and inlet valve closure. The output is CA50. This model is referenced as model 1. The second model, referenced as model 2 , has two additional inputs. These are the amount of injected fuel per cycle and engine speed (rpm).

To identify the Simulink model a MATLAB script was used. This script ran the model several times, collecting data from the different states. The model was excited with PRBS (PseudoRandom Binary Sequence) signals with different amplitudes and periods. In the identification of model 1 two of the inputs were held constant. The resulting data from the model was stored in five arrays containing the inlet temperature, amount of injected fuel per cycle, engine speed, inlet valve closure and CA50. The arrays were converted to two iddata objects (containing input, output and sample time) where one is for identification and the other for validation. The MATLAB command n4sid was used to calculate a state space model of arbitrary order and the model is linearized around an operating point. Further, the command compare is used to validate the model with the validation data. 


\subsection{Control design}

The controller is designed using the model 1 and LQG control is chosen as the control structure. This controller is easy to implement and is not time consuming. To design the controller the command dlqr was used to calculate the optimal gain matrix for the state feedback. The states were estimated by using the command kalman which calculates a Kalman filter. The command lqgreg was used to connect the Kalman filter with the optimal gain matrix to form the controller. 


\section{Results}

\subsection{The modeling}

1. The pressure change due to valve closing and opening can be seen in Figs. 1 and 2. Note pressure in [Bar].

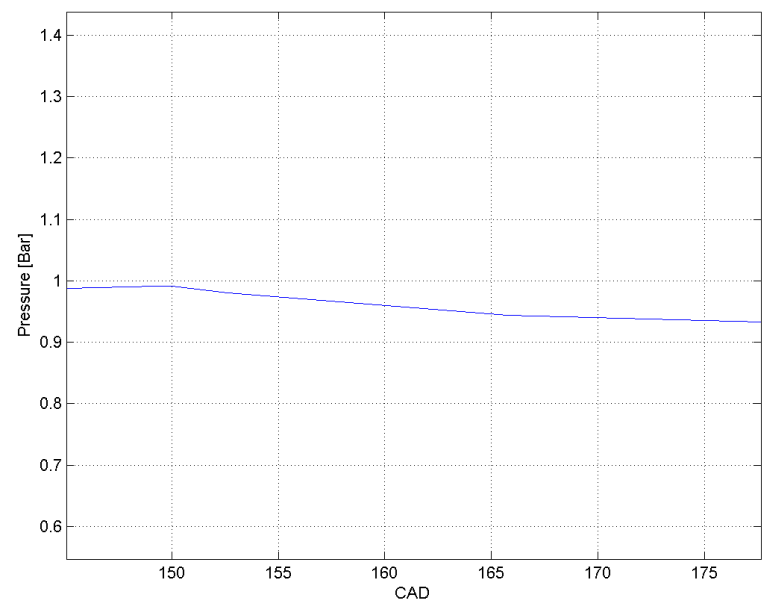

Figure 1: Pressure drop due to closing of the inlet valve at $150 \mathrm{CAD}$

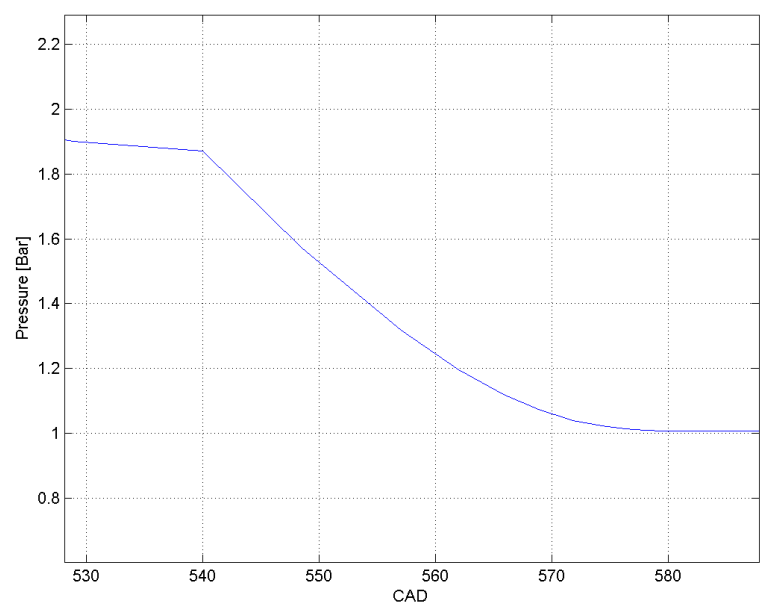

Figure 2: Pressure drop due to opening of the exhaust valve at $540 \mathrm{CAD}$ 
2. The fast rising of the pressure due to combustion can be seen in Fig. 3 . Note that the combustion is initiated around 360 CAD.

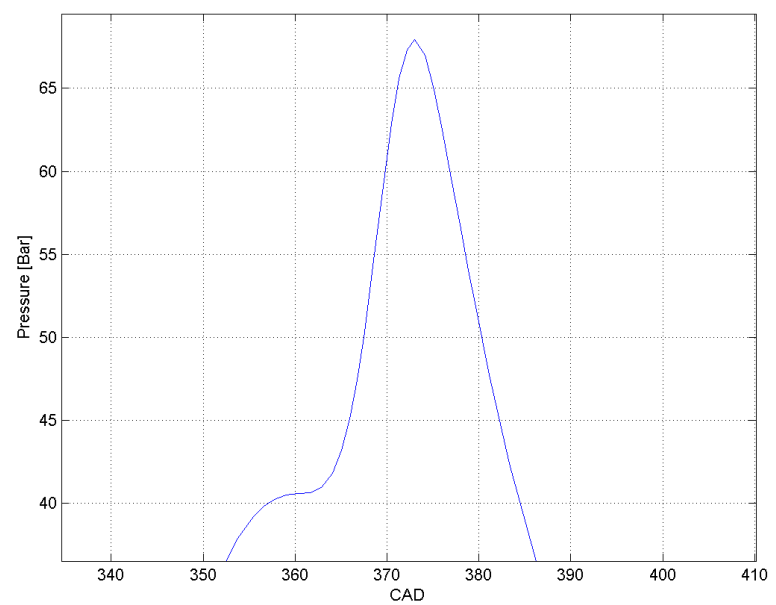

Figure 3: Pressure change due to combustion

3. The cold start-up cycle and the second cycle with warm residuals can be seen in Fig. 4. Note that the lower curve corresponds to the start-up cycle.

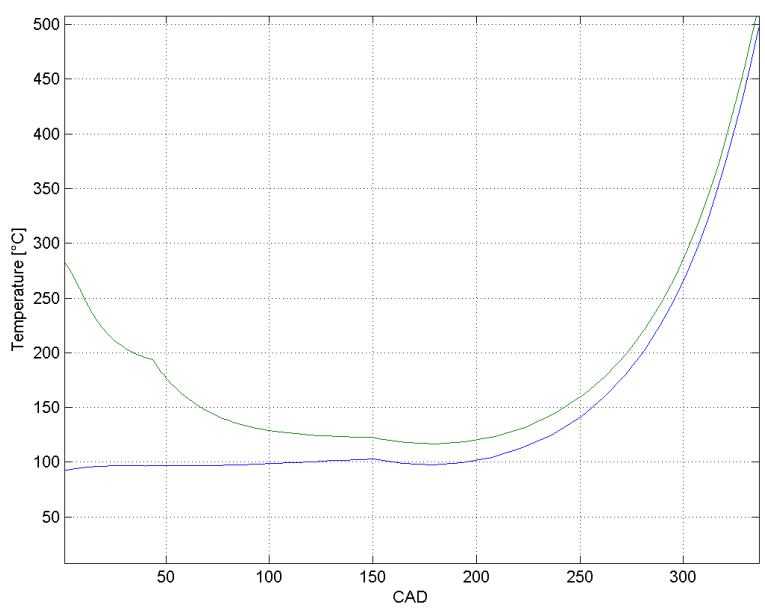

Figure 4: Temperature traces of cold and warm cycle. 
4. Fig. 5 shows the temperature trace. The inlet temperature is around 100 degrees Celsius giving an exhaust temperature of around 300 degrees Celsius. Note that this cycle has no warm residuals.

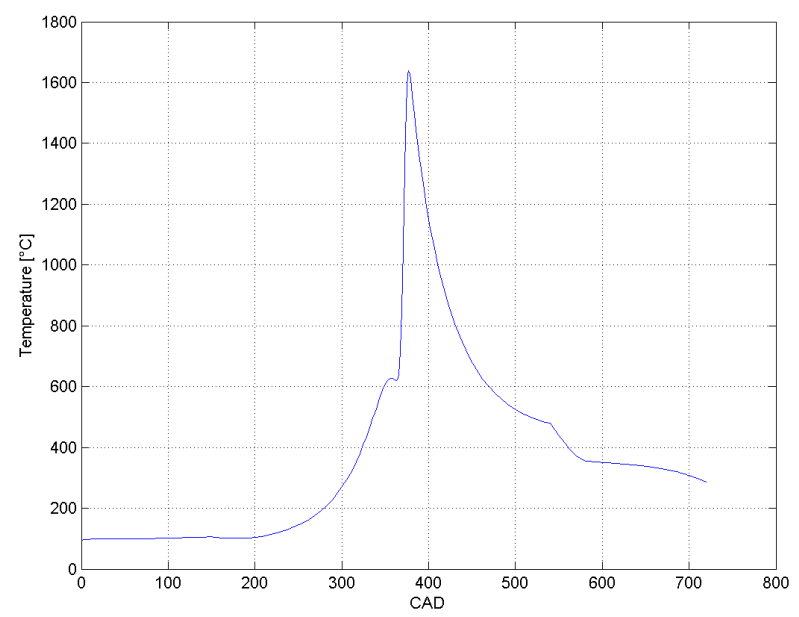

Figure 5: Temperature curve of a complete cycle.

5. Fig. 6 shows how CA50 changes when the inlet temperature rises 10 degrees.

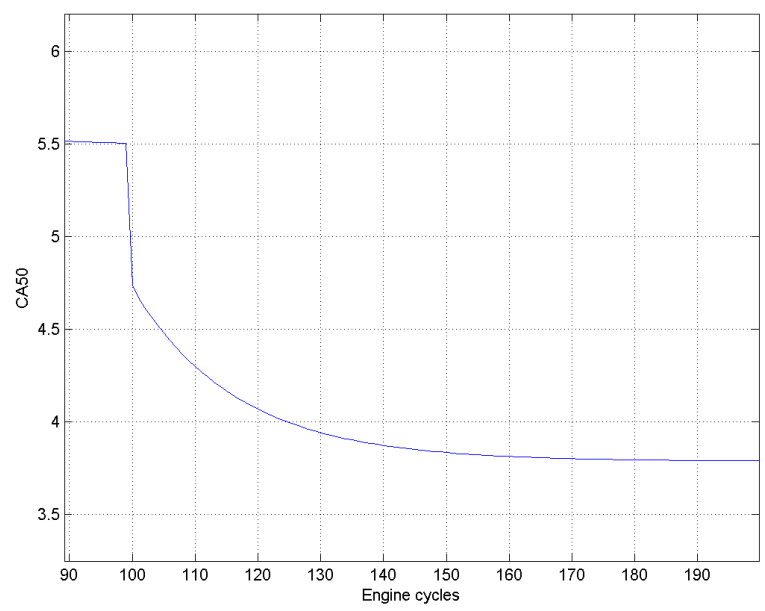

Figure 6: Effects on CA50 from a step in inlet temperature. 
6. Fig. 7 shows the wall temperature during a complete cycle.

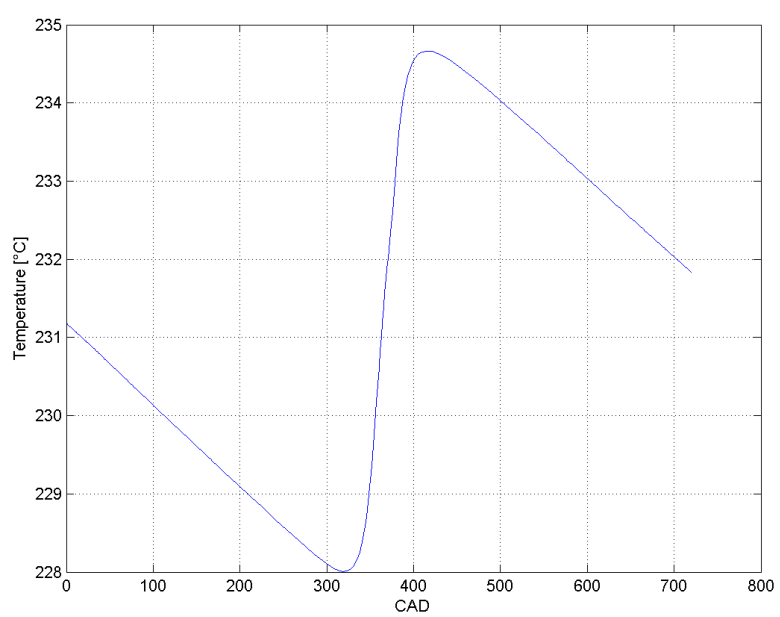

Figure 7: Temperature of the cylinder walls during a complete cycle.

7. Fig. 8 shows the temperature of the walls when the inlet temperature is raised by 10 degrees.

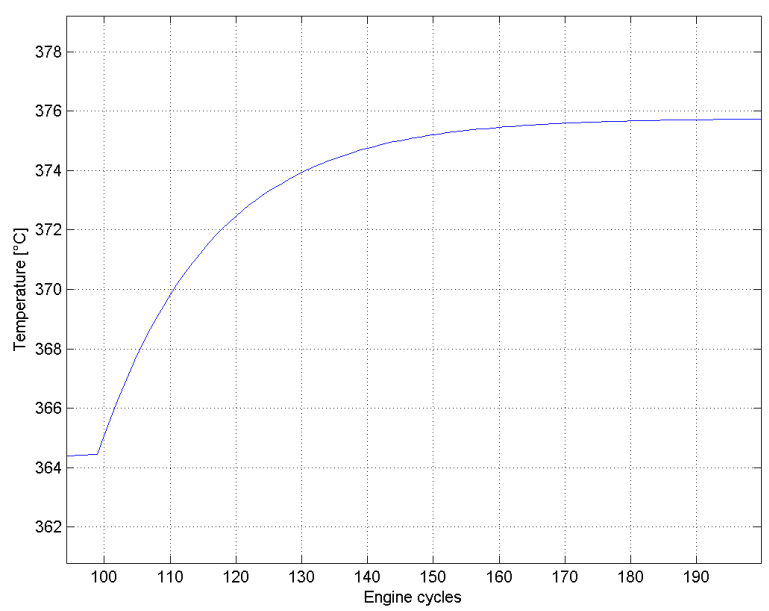

Figure 8: Temperature of the walls when the IVC is advanced with 10 degrees

8. Figs. 26 to 30 in A.1 show the concentrations of the different species. To calculate the mass before and after the combustion it is possible to take out two points in each figure and calculate the mass per volume unit. See appendix for calculations. Mass before combustion is $1.88 \cdot 10^{-3} \mathrm{~kg}$ and after $1.88 \cdot 10^{-3} \mathrm{~kg}$. 
9. Fig. 9 and 10 shows the inflow and outflow. Inlet valve closes at $150 \mathrm{CAD}$ and exhaust valve opens at $540 \mathrm{CAD}$.

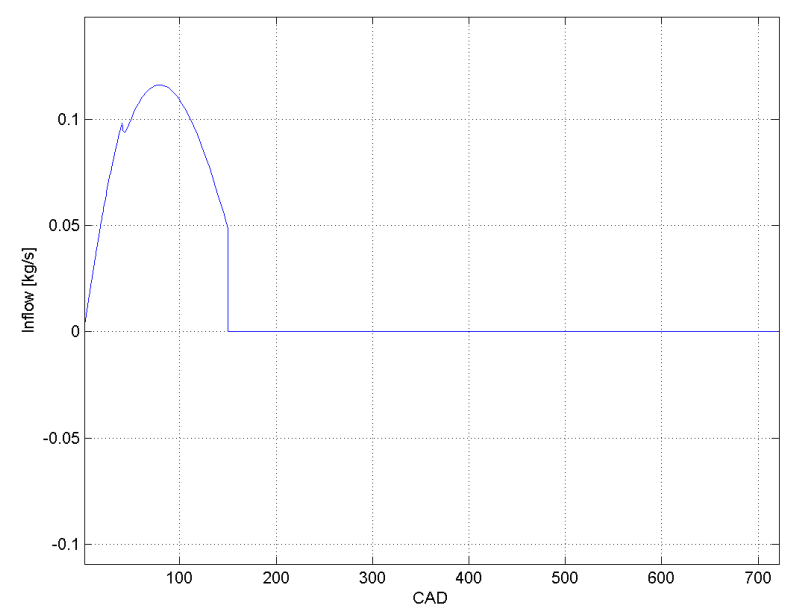

Figure 9: Inflow of mass to the cylinder.

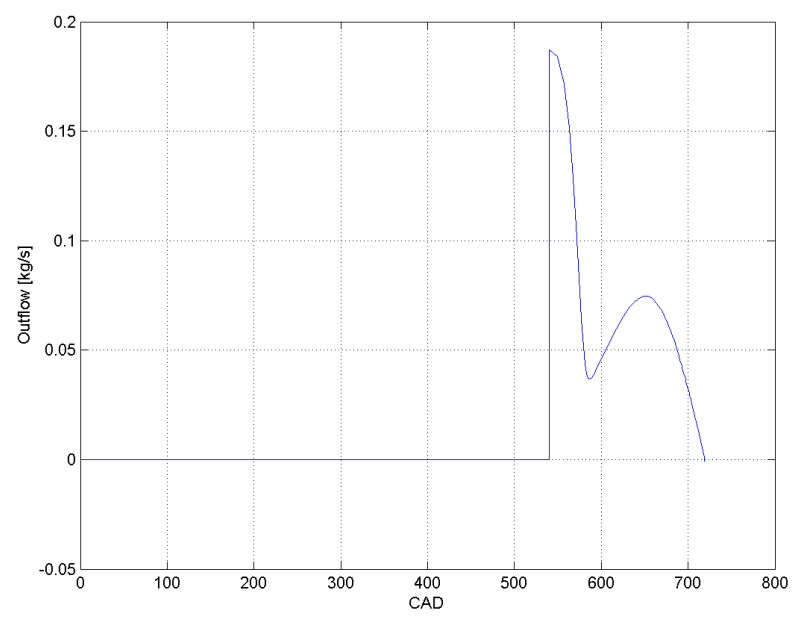

Figure 10: Outflow of mass from the cylinder. 
10. Fig. 11 shows the step response in $\mathrm{rpm}$.

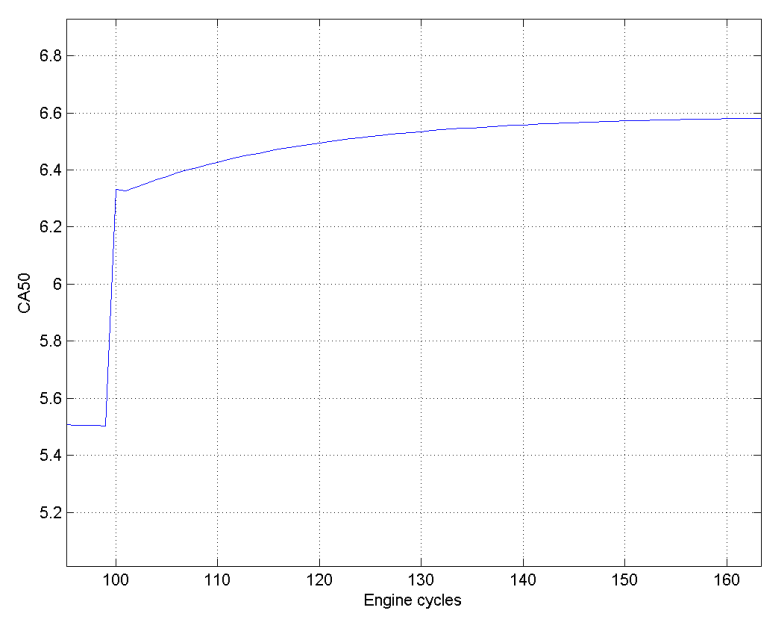

Figure 11: Effects on CA50 of a step by 100 in rpm.

11. Fig. 12 shows the step response when the injected amount of fuel is raised by $100 \mathrm{~J}$.

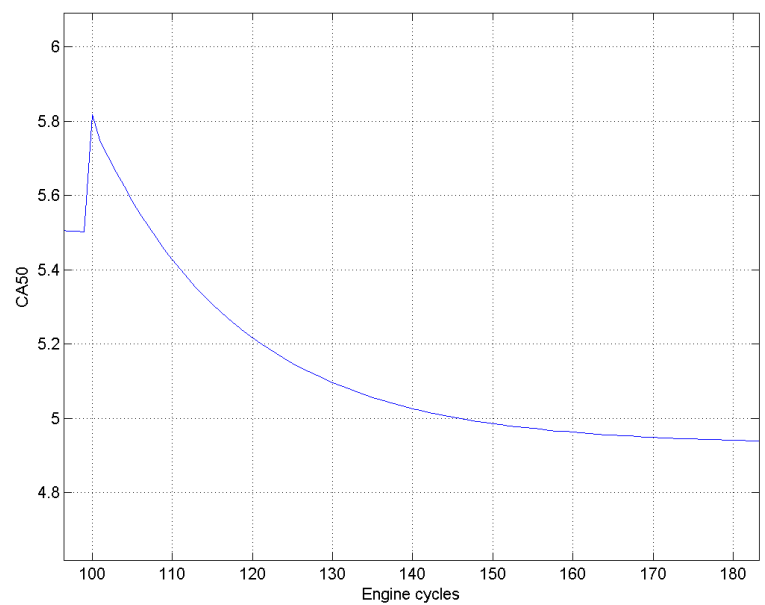

Figure 12: Effects on CA50 of a step in injected amount of fuel. 
12. Fig. 13 shows the step response when inlet valve closes 10 degrees earlier.

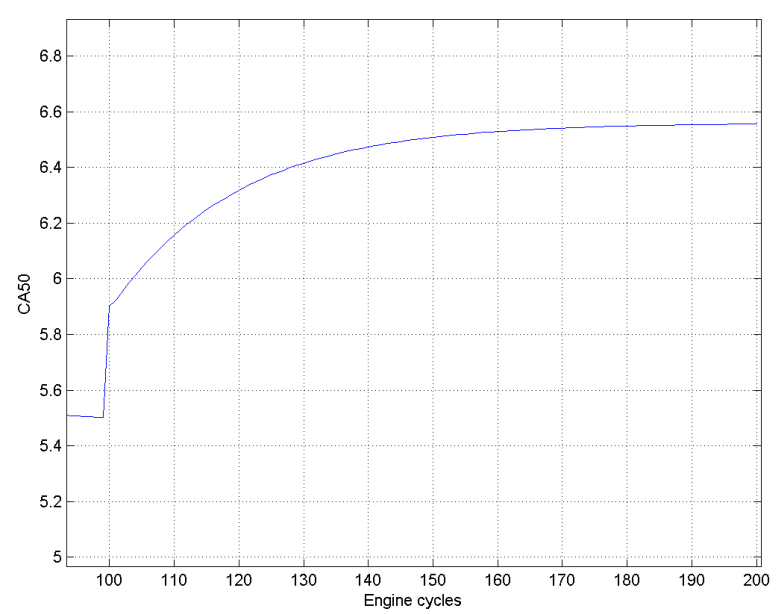

Figure 13: Effects on CA50 of a step in inlet valve closure.

\subsection{Noise}

1. The white noise doesn't affect CA50 significantly. The constant offset disturbs more.

2. Same result as for the fuel noise but the CA50 fluctuates a bit more.

3. A small change in the coefficients which describe the heat transfer from and to the walls results in greater changes in CA50 than above disturbances. 


\subsection{Wall model behavior}

The relationship between CA50 and the wall temperature can be seen in Fig. 14. The effects on the wall temperature by changing the inlet temperature and IVC can be seen in Figs. 15 and 16

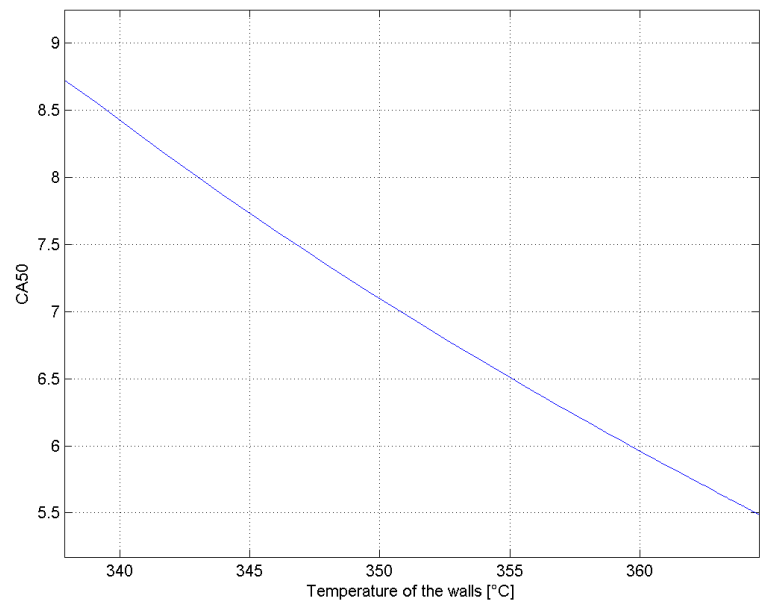

Figure 14: CA50 dependence of the wall temperature.

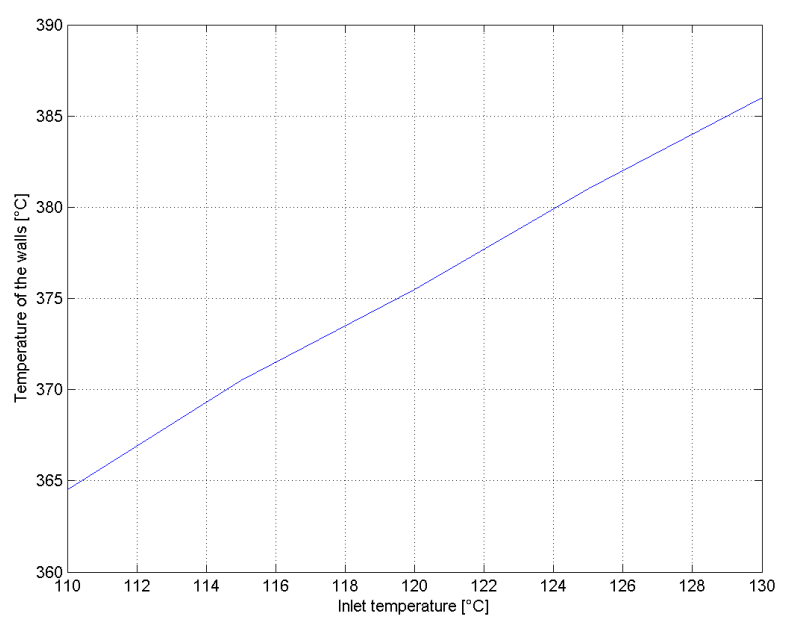

Figure 15: Wall temperature versus inlet temperature. 


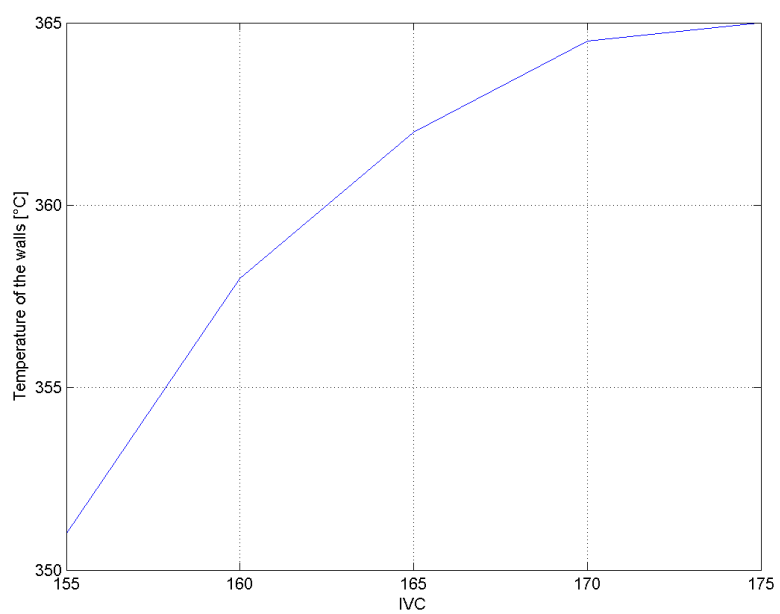

Figure 16: Wall temperature versus inlet valve closure.

\subsection{The calibration}

The Arrhenius threshold was adjusted to a stationary point from the engine and a step response was initiated by increasing the injected amount of fuel. The CA50 drop from around 5.5 to 3 CAD after TDC in around 100 cycles. The wall model was adapted to this result and no further engine data was needed.

\subsection{The identified model}

Different model orders where investigated and validated with the validation data from 4000 cycles. A model-order of 1 gave the best fit when the prediction horizon where changed between 1-5 steps ahead. This model order was chosen and proved to be stable as well for both model 1 and 2 .

\subsection{The controller}

The controller was designed using the model 1 . Since the controller is of order 1 there exists two parameters which can be adjusted for best performance. These parameters are used to minimize the cost function.

When the controller was tested on the model 2 it was able to control the CA50 but with a stationary error. To fix this an integrating state was added to the control design and two more adjustable parameters were introduced as gains for the integrating state feedback to the two controller outputs. By changing the integrator gains the controller was able to drive the error to 0 which corresponds to drive the output of model 2 to 0 . When designing the controller it's critical that the outputs don't exceed the physical limits of the actuators chosen to control the engine. The control signals when controlling the model can be seen in Fig. 17 and 18. The corresponding CA50 can be seen in Fig. 19. 


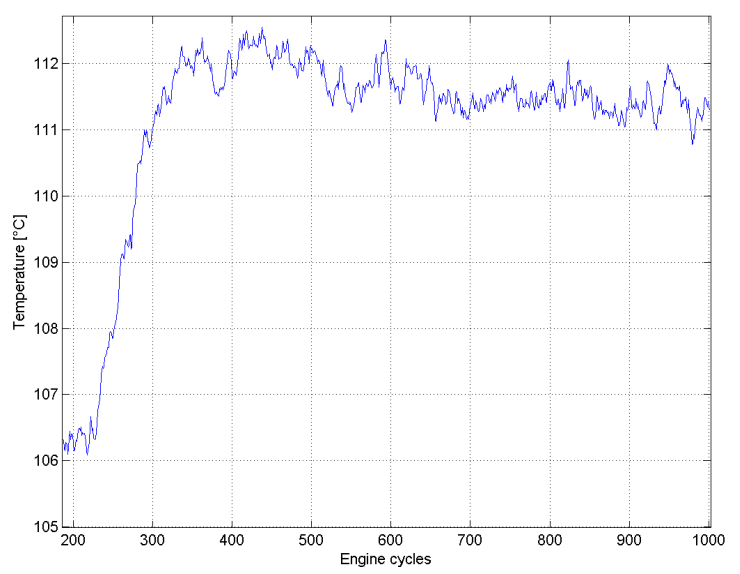

Figure 17: The temperature control signal during a positive step in rpm when controlling the model.

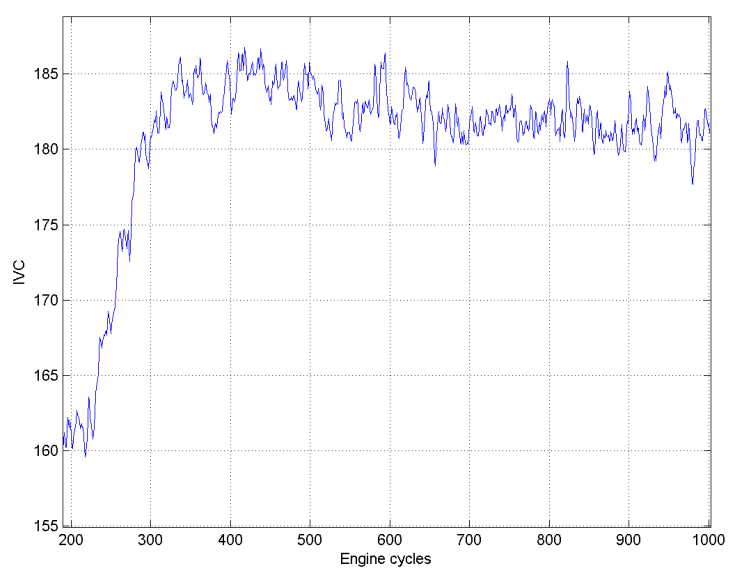

Figure 18: The IVC control signal during a positive step in rpm when controlling the model. 


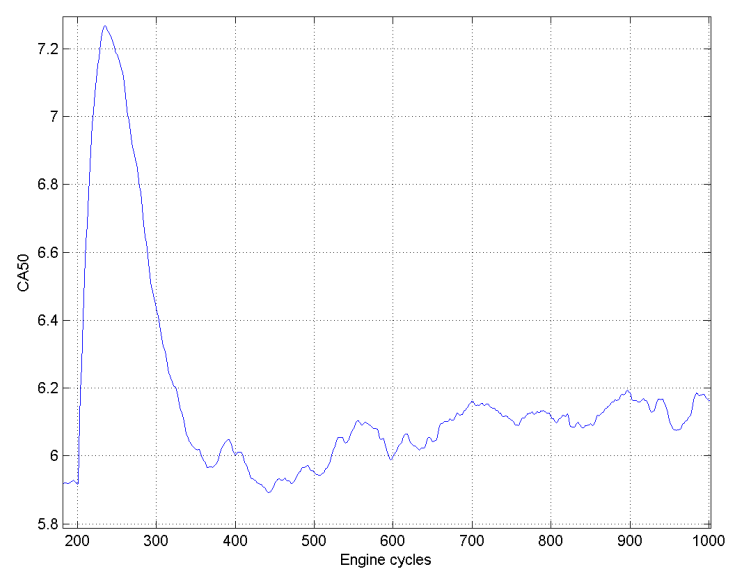

Figure 19: CA50 during a step in rpm when controlling the model.

The corresponding control signals when controlling the real engine can be seen in Figs. 20 and 21. The change in engine speed is to be seen in Fig. 22 and the CA50 from the running engine can be seen in Fig. 23.

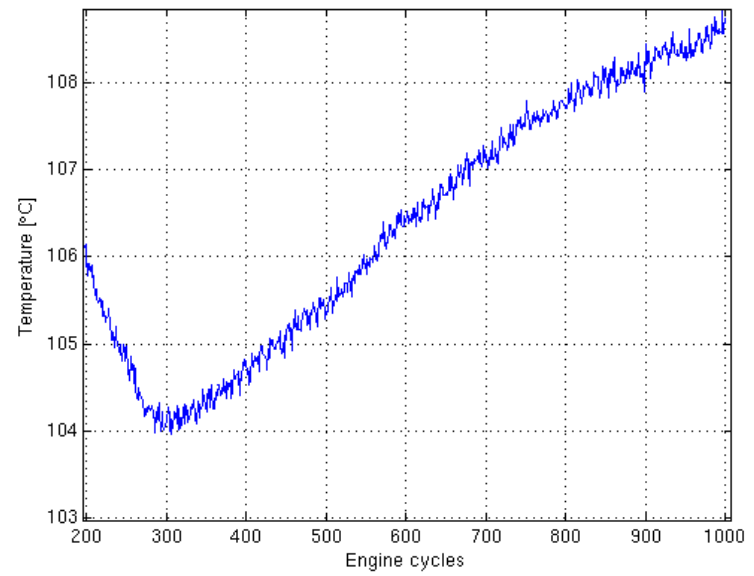

Figure 20: The temperature control signal during a positive step in rpm when controlling the engine. 


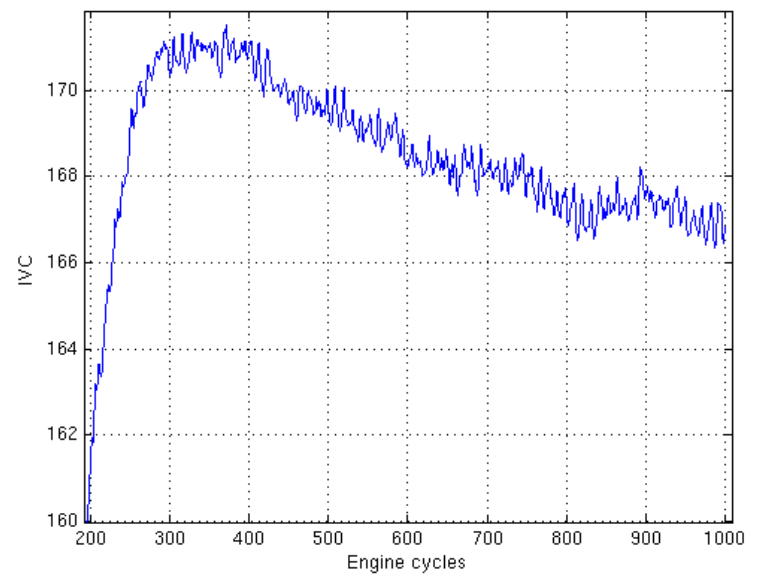

Figure 21: The IVC control signal during a positive step in rpm when controlling the engine.

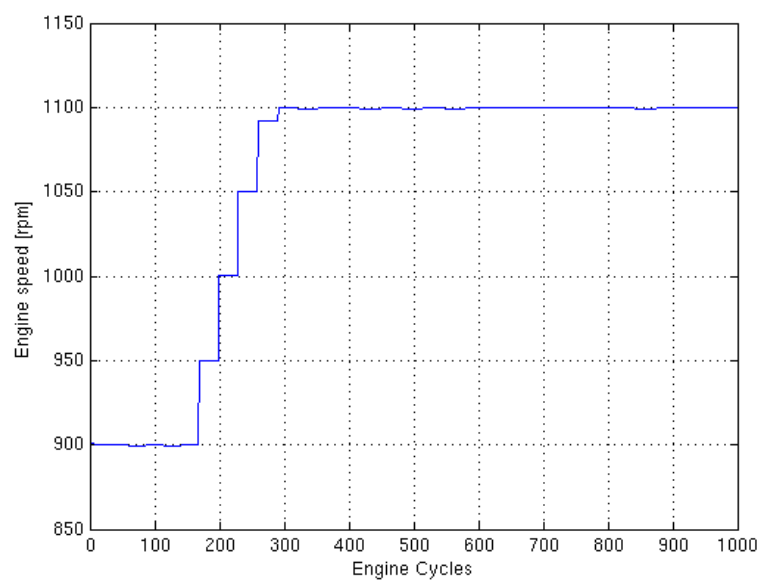

Figure 22: The change in engine speed from 900 to $1100 \mathrm{rpm}$. 


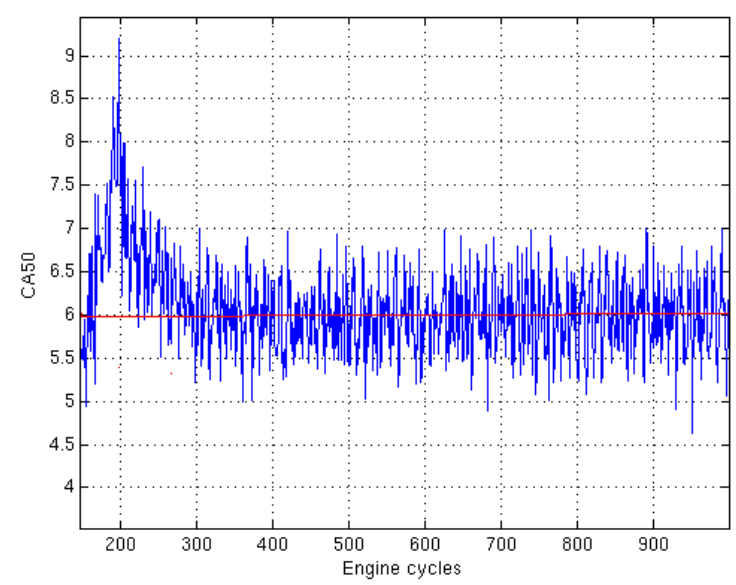

Figure 23: CA50 during a step in rpm when controlling the engine.

Further, Fig. 24 shows a step in the reference of the desired CA50 from 6 to 8 degrees after TDC and the corresponding control signal of the IVC in Fig. 25 during the control of the real engine. The temperature control signal did not change significantly during the change in CA50 reference.

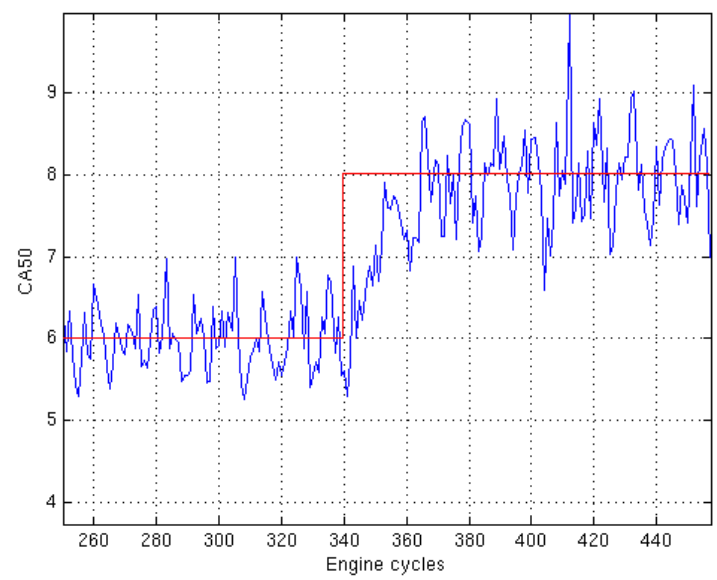

Figure 24: CA50 during a reference change from 6 to 8 degrees after TDC. 


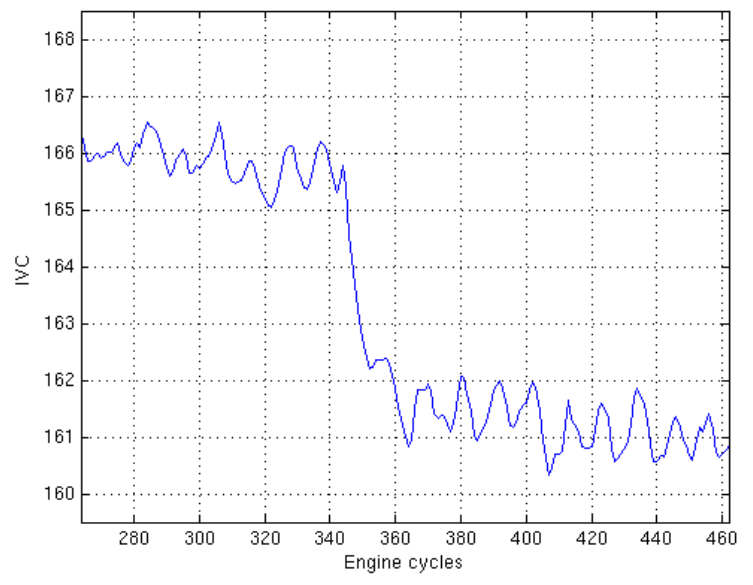

Figure 25: The IVC control signal during a positive step in rpm. 


\section{Discussion}

\subsection{The modeling}

The Simulink model became very complex and time consuming, see Fig. 31 for a picture of it. By inspection of the model, all parts of it are necessary to give the final desired result, the CA50. The question is if it's possible to reduce the model and still capture the dynamics of the CA50. There are parts which are essential meaning they affect CA50 more than others. One of these parts is the wall model which seems to affect CA50 more than anything else. The parameters in the model controls the heat flows and with different parameters the characteristics of the CA50 will vary significantly. With one parameter configuration the CA50 will have a positive response to steps in the amount of injected fuel and with another configuration the result will be a negative response. These different responses depend on the estimated wall temperature. In some cases the wall temperature goes up far over the temperature of the water surrounding the cylinder. This can be explained with the fact that the model used in the modeling of the cylinder wall temperature is simple and one dimensional. It doesn't take into account the fact that the piston may be significantly hotter than the walls due to the poor cooling. Further, the cooling around the valves may be poor as well as some areas around the inner top of the cylinder.

When dealing with the wall model it may be possible that it behaves as a real engine when it comes to calculate the heat flows but it fails to calculate an estimate of the wall temperature. This may be sufficient if the CA50 from the model behaves as the CA50 from the real engine and the wall temperature can be seen as a state which has no direct correspondence to the real engine.

\subsubsection{The tests}

The pressure drop of the in-cylinder pressure due to closing of the inlet valve originates from the ideal gas law meaning that the amount of species is constant but the volume is increasing. This will lower the pressure. The pressure drop when opening the exhaust valve is a result of the high pressure after the combustion forcing the mass out of the cylinder.

The comparison between the cold and warm cycle shows that hot residuals affect the in-cylinder temperature during the intake phase and beginning of compression phase. This behavior can be seen as a coupling cycle-to-cycle and is one part of the engine dynamics.

When inlet temperature is raised the CA50 is decreased. This is intuitive as a higher temperature favors exothermal reactions and the combustion is triggered earlier. The greater temperature of the gas raises the temperature of the walls. This can be explained by the fact that the walls are exposed to a higher temperature during the same amount of time. The graph of the temperature of the walls follows the theory and is to be interpreted as a low pass filtering of the temperature of the in-cylinder gas since this is the source of heat.

The calculation of masses before and after the combustion indicates that the mass is constant. This is obvious since there is no mass flow from and to the cylinder during the combustion. The flow of mass to the cylinder via the inlet valve follows the velocity of the piston meaning that the highest flow occurs 
when the piston has its greatest speed. This is logical since the velocity of the piston is the length it has traveled in a constant amount of time and this is proportional to the swept volume. The flow via the exhaust valve shows a great flow peak in the beginning of the outlet phase. This is due to the high pressure in the cylinder after the combustion and the atmospheric pressure outside the cylinder. After the transient the flow follows the piston speed.

The effect on CA50 from the change in rpm can be explained by two reasons. The first is explained by the definition of CA50. The CA50 is the point where $50 \%$ of the fuel is burnt in CAD. A greater speed of the engine and a constant time of the combustion duration give rise to a combustion which in CAD is longer and by this the CA50 will be delayed. The other reason is the time the walls are exposed to the hot gas. A greater rpm lowers the time the cylinder walls are absorbing heat and the cooling outside the cylinder is approximately constant. This leads to colder walls and delaying of CA50.

The injected amount of fuel step response shows something unusual. The CA50 is first delayed followed by an advance. The summary is an advance by CA50. The total behavior without the transient is intuitive since more fuel per cycle leads to more molecules which can trigger the combustion. Further, more energy per cycle means more energy to the cylinder walls. This leads to hotter walls and earlier CA50. The non-minimum-phase behavior in the transient can be explained by the heat capacity of the fuel. When more fuel is injected this fuel steals energy from the gas and this will delay CA50 because of the lower total temperature. After a number of cycles with more fuel per cycle the temperature of the walls has been raised and this compensates the lower temperature of the gas mixture.

During a step in IVC meaning that the inlet valve is closed $10 \mathrm{CAD}$ earlier the CA50 was delayed. This has a straight forward explanation that less mass is sucked into the cylinder leading to a smaller compression-ratio which lowers the maximum temperature from the adiabatic compression.

If noise is introduced in the model the CA50 does not change significantly. This has to do with the integrator in the Arrhenius rate threshold. A small amount of white noise added to the signals will almost disappear after the integration.

As can be seen in Fig. 14, a linear relation holds between CA50 and the wall temperature. The importance of a wall model is clear since a change by ten degrees in temperature gives a change in CA50 by 1 CAD. When dealing with a temperature span of almost 2000 degrees in the gas-mixture the resulting effect on the temperature of the walls needs attention. This leads to the fact that an approximation of the wall temperature by $400 \mathrm{~K} \mathrm{[3]}$ is not accurate enough. Further, the wall model introduces dynamics into the model making a cycle-tocycle connection. This is important since the dynamics describe how fast the change in wall temperature and CA50 depends on IVC and inlet temperature steps.

By looking at Fig. 15 the wall temperature tends to follow the inlet temperature linearly. A raise by ten degrees in inlet temperature raises the wall temperature by approximately ten degrees. This shows that the walls are exposed by a ten degrees hotter gas during a complete cycle and this must raise the temperature of the walls by an equal amount when steady state has been reached in the walls.

When it comes to changing the IVC, see Fig. 16. The relation between 
IVC and wall-temperature are not linear. The IVC corresponds to how much mass is sucked into the engine and this is non-linear since the volume of the cylinder is almost sinusoidal. More mass in the cylinder means a higher effective compression-ratio and higher compression-temperature which raises the temperature of the walls.

The results from the tests of the wall model can be used to set up controlstrategies for the engine. Given a desired CA50 as a reference and the current CA50 is delayed by some CAD the controller should be able to raise the inlet temperature and IVC to advance the CA50 towards the desired reference. On the other side a too early CA50 can be avoided by lowering the inlet temperature and IVC. The process dynamics is described by the dynamics in the wall model after the initial transient which occurs after every change in inlet temperature and IVC see Fig. 13 for example.

\subsection{The identified model}

The model which gave the best prediction was of order 1 . This was expected since the cycle-to-cycle dynamics in the Simulink model originate from the wall model. This wall model is of order 1 and can be seen as a low-pass filter. Tests with higher orders gave models which became close to unstable. The greatest advantage with a low order model is that the resulting controller is of low order and therefore simple and fast when used as a part of a greater engine control system.

\subsection{The controller}

Temperature changes are known to be slow and this fact is critical for the adaptation of the inlet temperature control signal. The inertia of this signal must correspond to the inertia in the heater. This is a limit which must be calibrated using the real engine. To design this optimal control signal the integrator must have greater effect than the signal from the pure LQG controller. The design of the signal which controls the inlet valve closure is different. This signal can vary arbitrarily cycle-to-cycle. With these two different signals it's possible to design a controller with enough performance. To remove an error caused by a load disturbance the inlet valve closing signal grows fast during the slow change of the temperature. When the temperature has begun to change significantly the inlet valve closing signal can return towards its previous value. This behavior can both control the CA50 and respond to fast changes in load disturbances.

When it comes to controlling the real engine the controller was not able to change the temperature signal enough to let the IVC signal return to the desired value. This is caused by the fact that the LQG-controller in itself has no ability to favor some signals in a more advanced way than using a weighting matrix. In the step change in rpm the temperature initially goes at the wrong direction see Fig. 20. This depends on the flow through the heater. If the engine speed is increased the greater flow will cool the heater until it has reached the old temperature since temperature changes are slow. This fact can explain why changes in rpm take longer time than changes in the desired CA50. The behavior of the temperature affects the IVC signal which reaches its maximum when the temperature is low see Fig. 21. During the rise in temperature the IVC goes down to reach the new stationary point. 
An alternative to the LQG-controller here would be a midrange-controller [5] which has the benefit of controlling a process and controlling the controllers signals in a desired way. Implementing this controller is not a part of the thesis work.

\subsection{Conclusions}

By implementing equations for different states which describes an engine, a complex model which solves the equations can be used to simulate an engine stroke. The expected behavior of the different parts of the model corresponds well to the behavior of a real engine. With this result the model can be used as a base for designing controllers for an engine.

To control CA50, physical modeling is one way towards the design of a controller. To describe the dynamics of the engine a wall model can be used. This model serves as a coupling cycle-to-cycle and is of low order. Further, the temperature of the walls can be seen as a state which accumulates and low-pass filters all events which give rise to a temperature change of the gas mixture.

The LQG-controller with added integrating states can be used to control CA50 of the engine. The controller can handle both reference steps and stationary control of CA50. With knowledge of the limitations for the inlet temperature and IVC a different controller may be used to control the behavior of the control signals.

\subsection{Further development}

To extend the operating range of the CA50 controller, control of the inlet pressure is one way. This must be done in two steps where the first one is to design a controller for the VGT-valve on the turbo. This controller should take a pressure reference and control the vanes in such a way that the desired pressure is held approximately constant. This can be difficult under low load circumstances. The second step is to implement the new CA50 controller with three control signals. The industrial heater can be replaced by a heat exchanger from exhaust to inlet gas. This saves energy and might be faster since the inlet air temperature is controlled by a valve which controls the amount of exhaust through the heat exchanger. This system only works when the exhausts are warm which can be solved by running the engine on diesel until the exhausts are warm enough. 


\section{Bibliography}

\section{References}

[1] Rolf Egnell Alternative Fuels Grön Bil and Aspen Utvecklings AB 2006

[2] J.Bengtsson, P.Strandh, R.Johansson, P.Tunestål and B.Johansson Hybrid control of homogeneous charge compression ignition (HCCI) engine dynamics International Journal of Control Vol. 79, No. 5, May 2006, 422-448

[3] G.Shaver, M.Roelle \& C.Gerdes Modeling cycle-to-cycle dynamics and mode transition in HCCI engines with variable valve actuation. Control Engineering Practice 14 (2006) 213-222

[4] Steven R. Turns An Introduction to Combustion: concepts and applications 2nd ed. McGraw-Hill 2000

[5] M.Karlsson, K.Ekholm, P.Strandh, R.Johansson, P.Tunestål and B.Johansson Closed-loop control of combustion phasing in an HCCI engine using VVA and variable EGR. To be published in Fifth IFAC Symposium on Advances in Automotive Control, 2007 


\section{A Appendix}

A.1 Calculation of masses before and after combustion The concentrations of species are shown in Figs. 26 to 30.

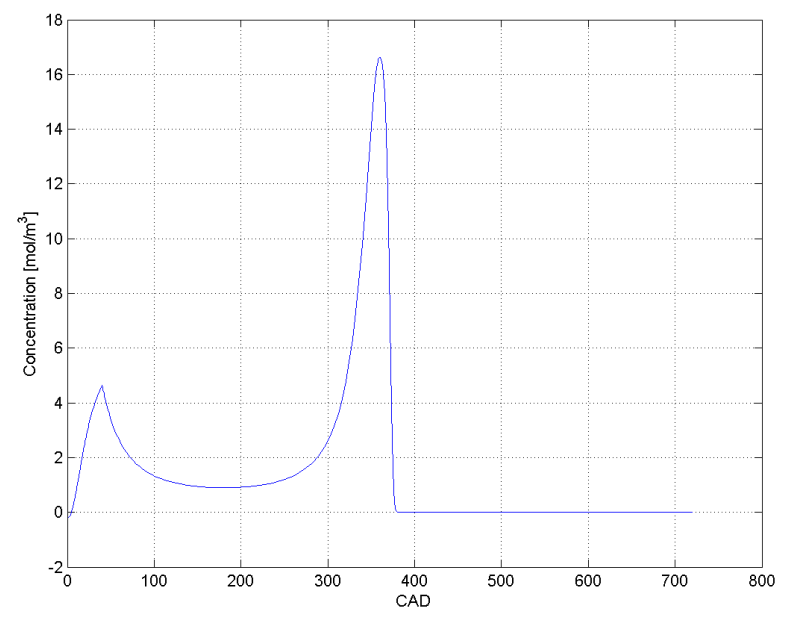

Figure 26: Concentration of fuel.

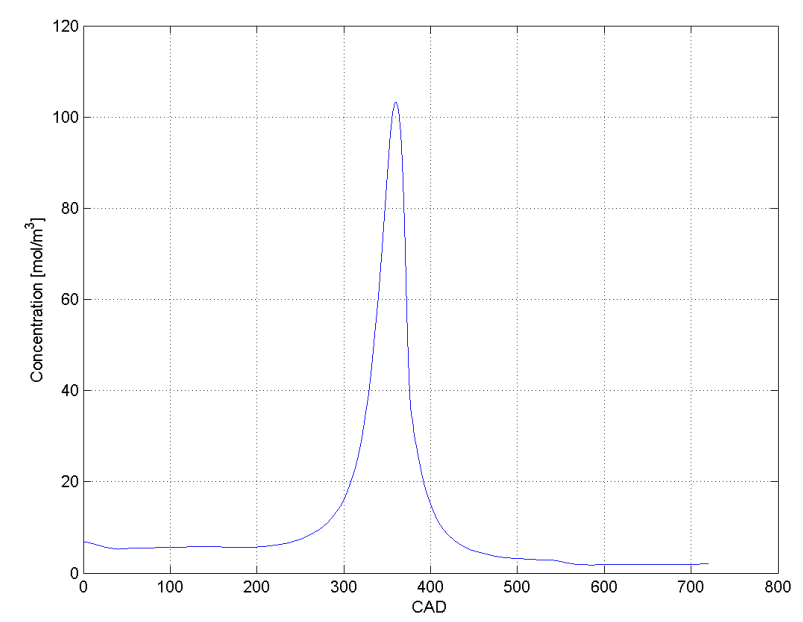

Figure 27: Concentration of oxygen. 


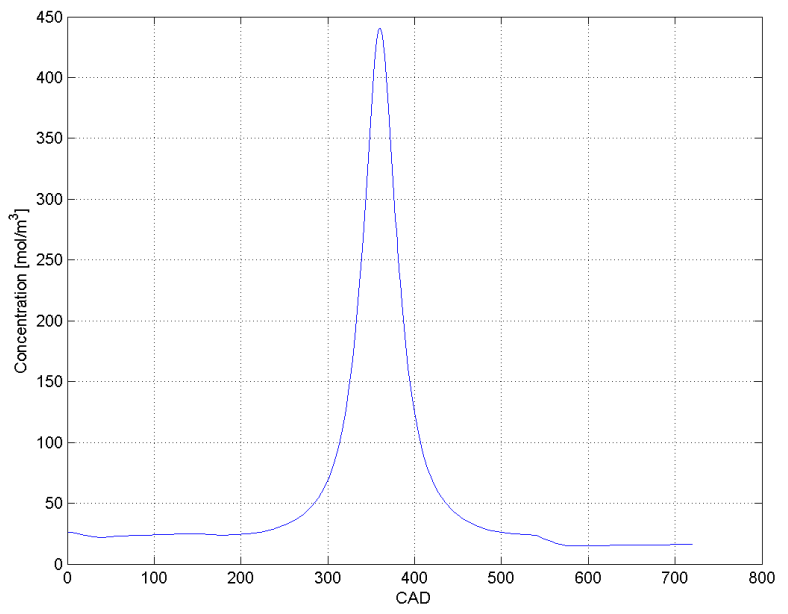

Figure 28: Concentration of nitrogen.

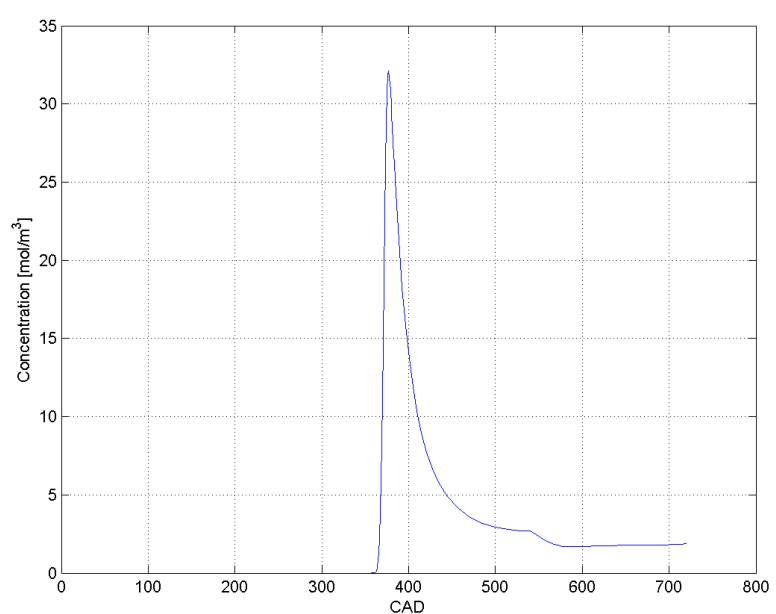

Figure 29: Concentration of water. 


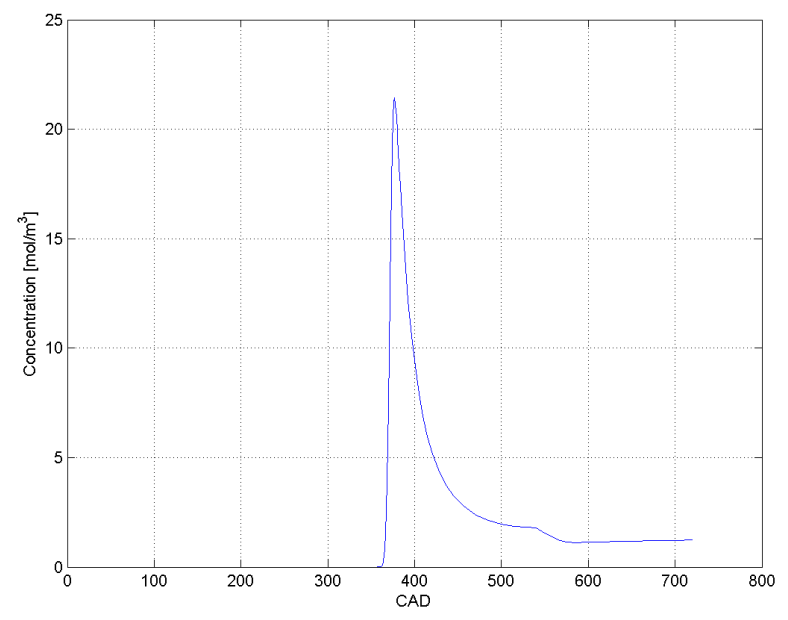

Figure 30: Concentration of carbon dioxide.

Species Before combustion $\left[\mathrm{mol} / \mathrm{m}^{3}\right] \quad$ After combustion $\left[\mathrm{mol} / \mathrm{m}^{3}\right]$

$\begin{array}{ccc}\text { Fuel } & 1.18 & 0 \\ \text { Oxygen } & 12.7 & 9.0 \\ \text { Nitrogen } & 54.5 & 54.5 \\ \text { Water } & 0 & 3.5 \\ \mathrm{CO}_{2} & 0 & 2.4\end{array}$

The volume before and after the combustion is $9.5 \cdot 10^{-4} \mathrm{~m}^{3}$ and the formula: $n_{\text {fuel }} \cdot M_{\text {fuel }}+n_{\text {oxygen }} \cdot M_{\text {oxygen }}+n_{\text {nitrogen }} \cdot M_{\text {nitrogen }}+n_{\text {water }} \cdot M_{\text {water }}+n_{\mathrm{CO}_{2}} \cdot$ $\mathrm{M}_{\mathrm{CO}_{2}}$ is used to calculate the masses.

Mass before combustion is $1.88 \cdot 10^{-3} \mathrm{~kg}$ and after $1.88 \cdot 10^{-3} \mathrm{~kg}$. 


\section{A.2 The Simulink model}

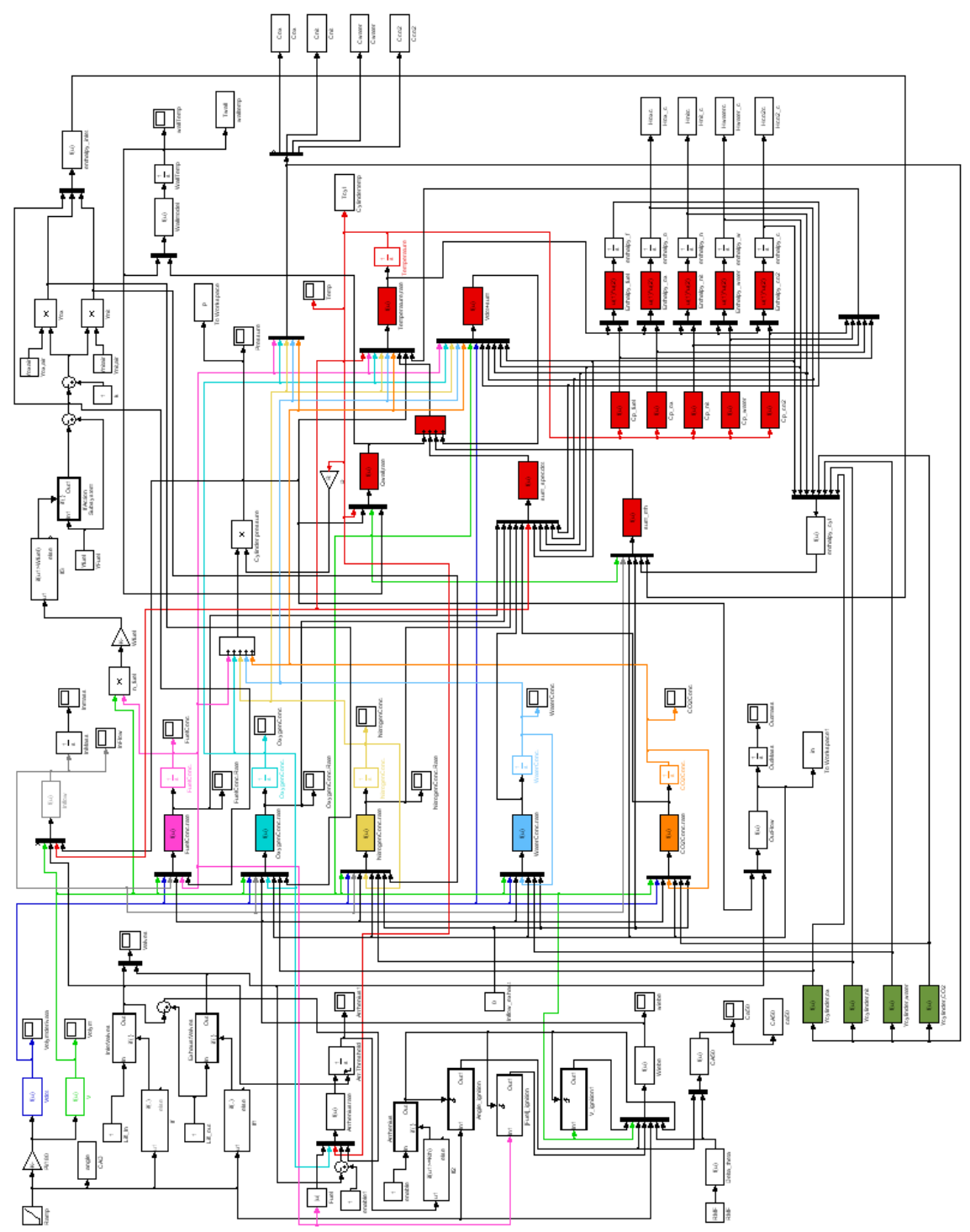

Figure 31: The Simulink model 
